\title{
State Practice Variations in the Use of Tube Feeding for Nursing Home Residents with Severe Cognitive Impairment
}

\author{
Judith C. Abronheim, MD, * Michael Mulvihill, DrPH, Carol Sieger, JD, $\neq$ Pil Park, PhD, ${ }^{\S}$ and \\ Brant E. Fries, $\mathrm{PhD} / /$
}

OBJECTIVE: To describe the differences in prevalence of tube feeding among states and to examine possible factors that could explain practice patterns.

DESIGN: Analysis of random samples from an interstate data bank comprised of the Minimum Data Set (MDS), a standardized, federally mandated assessment instrument for nursing home residents.

SETTING: Nursing homes in four states participating in a federal demonstration project of case mix payment plus five others with existing MDS data systems.

PARTICIPANTS: Individuals 65 years of age and older $(\mathrm{N}=57,029)$, who had very severe cognitive impairment, including total dependence in eating, and who resided in nursing homes during 1994, the most recent year for which uniform data were available.

MEASUREMENTS: State-by-state differences in prevalence of tube feeding, controlling for demographic and clinical variables.

RESULTS: The prevalence of tube feeding ranged from $7.5 \%$ in Maine to $40.1 \%$ in Mississippi. Each state had a significantly elevated prevalence of tube feeding compared with Maine, with odds ratios (ORs) ranging from 1.50 to 5.83, $P<.001$. Specific directives not to provide tube feeding (OR 0.41, $P<.001$ ), and white race (OR 0.45, $P<.001)$ were strongly and negatively associated with tube feeding.

CONCLUSIONS: Wide regional variations exist in the use of tube feeding of nursing home residents with equivalent impairments. Sociodemographic factors could be important, but more study is needed to determine whether physician characteristics, such as race, attitudes, or knowl-

From the "Eileen E. Anderson Section of Geriatric Medicine, Department of Medicine, Saint Vincent's Hospital and Medical Center, New York, and New York Medical College, Valhalla, New York; ${ }^{\dagger}$ Department of Family Medicine and Community Health, Albert Einstein Col-

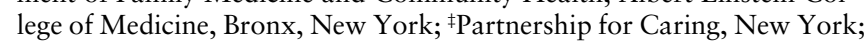
Institute of Gerontology, University of Michigan, Ann Arbor, Michigan; and Institute of Gerontology, University of Michigan and Health Systems Research, Ann Arbor VA GRECC, Ann Arbor, Michigan. Address correspondence to Judith C. Ahronheim, MD, Chief, Eileen E. Anderson Section of Geriatric Medicine, Saint Vincent's Hospital and Medical Center, 153 W. 11th Street, NR 1221, New York, NY 10011. edge, have an impact and to clarify medical standards for the use of tube feeding in this population. J Am Geriatr Soc 49:148-152, 2001.

Key words: enteral nutrition; nutritional support; nursing homes; advance directives; mental competency

$\mathrm{T}$ he decision of whether to use enteral feeding tubes (tube feeding) to provide nutritional support for incompetent residents in long-term care facilities is highly controversial. Long-term tube feeding is commonly used in patients with advanced neurological impairments, but there are no data describing practice patterns under these circumstances.

Ethicists, medical and nursing professional societies, and courts concur that decisions to forgo tube feedings or other forms of artificial nutrition and hydration (ANH) resemble decisions about other medical treatments, ${ }^{1-5}$ but there is greater reluctance to discontinue ANH..$^{6-8}$ The U.S. Supreme Court has twice affirmed a person's right to forgo ANH, ${ }^{9-10}$ but the Court gave states wide latitude to establish procedures for such decisions for incompetent persons, including standards of evidence of a previously competent person's preferences. In fact, statutes in certain states delineate separate legal standards of decision making for $\mathrm{ANH}$, as compared with other medical treatments. ${ }^{11-13}$

Anecdotal experience suggests that indications for tube feeding vary widely among physicians. In addition to legal and ethical controversy, there may be uncertainty among physicians about the indications for tube feeding. This uncertainty may stem from "myths" that prevail with regard to the benefits and burdens of tube feeding in end-stage illness, ${ }^{14}$ which could in turn lead to inconsistent or highly variable application of this treatment.

The goal of this study is to describe the variation in the prevalence of tube feeding among states and to examine possible factors that could explain practice patterns. The results should help clarify the standard of care and offer insights into the relationship to state policies or other prevailing factors.

\section{METHODS}

Under the Omnibus Reconciliation Act of 1987 (OBRA 1987), nursing homes in the United States are mandated to 
complete a standardized, comprehensive assessment of each resident upon admission, at regularly scheduled intervals, and if there is a significant change in the patient's status. The data from the Resident Assessment Instrument (RAI) Minimum Data Set (MDS) are used to develop a plan of care for each patient, ${ }^{15}$ and have shown good interobserver reliability. ${ }^{16}$

Data were obtained for the calendar year 1994 for states participating in a federal demonstration project of case mix payment (Maine, Mississippi, South Dakota, and New York) plus others with existing MDS data systems (Missouri, Nebraska, Ohio, Washington, and Wisconsin). This was the most recent year for which uniform data were available for all nine states. These states represent all states that by 1994 had computerized the MDS, except Kansas and Vermont, which had incomplete data at the time of analysis, and Pennsylvania, which collected assessments on a quarterly basis, making its data somewhat incompatible.

Subjects included all persons 65 years of age and older residing in nursing homes in the nine designated states during 1994 whose functional status was sufficiently severe that long-term tube feeding might have been recommended on that basis. This degree of impairment was defined as the highest category (level 6) on the 7-point Cognitive Performance Scale (CPS). The CPS is derived from specific MDS items, and enables the assignment of residents to a specific hierarchical level of cognitive function, ranging from 0 (cognitively intact) to 6 (very severely impaired). Level 6 , in addition, includes total dependence in eating. This scale has been previously used to delineate degree of cognitive function using MDS data, and validates well. ${ }^{17}$

Data represent all nursing homes in each state except Wisconsin, where submission of data by each facility was voluntary at that time. One assessment for each subject who met inclusion criteria was used in the analysis. When multiple assessments were available for one individual, the most recent full assessment was randomly selected within each category (admission, routine annual, and significant clinical change assessments, but excluding quarterly reviews). To determine whether state-by-state differences persisted after controlling for clinical and demographic variables, we examined the impact of age; gender; race; advance directives or other resident responsibility (e.g., legal guardian); existence of do-not-resuscitate (DNR) order, do-not-hospitalize (DNH) order, or a specific directive not to provide tube feeding; and specific diagnoses (Alzheimer's disease, other dementias, stroke, or Parkinson's disease). In the MDS, race is recorded as white, black, Hispanic, Indian, and Asian. Since whites constituted $90 \%$ of patients in the database, white race was used as the dummy variable and compared with all other groups (non-whites), and was the reference variable category in this analysis.

All analyses were performed using a SAS statistical package on a personal computer. ${ }^{18}$ Tests were considered significant at the 0.05 level, but, given the large sample size, the magnitude of differences (i.e., whether a difference was clinically important) was considered as well. Because facility submission of data in Wisconsin was voluntary, a separate analysis was performed that excluded data from that state. As this analysis yielded no meaningful differences, the full sample model is reported here.

State law governing medical decision making for individuals who lack capacity was analyzed for stringency with regard to forgoing ANH. Complexity of this law prevented the construction of a variable that could be given equal weight with other variables in a multivariate analysis. Thus, salient features of state law are described that illustrate separate standards for $\mathrm{ANH}$ as compared with other medical treatments.

\section{RESULTS}

A total of 61,603 nursing home residents from the nine states met the inclusion criteria and data on all variables were complete on 57,029 , or $92.6 \%$. The mean age of the study population was $84.8 \pm 8.1$ years; $77.7 \%$ were female. Other demographic and clinical characteristics of residents in each state are given in Table 1 . The proportion that received tube feeding ranged from $7.5 \%$ to $40.1 \%$. Maine, as the state with the lowest prevalence, was used as the reference for the dummy variables of the other states and is therefore the basis for interpreting the odds ratios for the states.

Resident characteristics and their association with the likelihood of receiving tube feeding are given in Table 2 . After accounting for clinical and demographic variables, nursing home residents in each state had a significantly elevated prevalence of tube feeding compared with the rate in Maine, with odds ratios ranging 1.50 to 5.84 . White residents were less than half as likely as non-whites to receive this treatment. Among the diagnoses considered, Alzheimer's disease and other dementias (OR 0.47 and 0.67, $P<.001$ ) were both strongly and negatively associated with tube feeding, while stroke was strongly predictive (OR 2.45, $P<.001)$. A medical power of attorney or living will was negatively associated with tube feeding (OR 0.75 and 0.68 , $P<.001$ ), and this association seemed particularly strong when there was a specific directive not to provide tube feeding (OR 0.41, $P<.001$ ). In contrast, legal guardianship and other legal oversight were not significantly associated. Those with DNR orders were more likely and those with DNH orders less likely to have tube feeding (OR 1.11, $P<.001$ and OR $0.86, P=.017$ ), but these associations were slight.

Analysis of state law as of 1994 revealed no separate standards for ANH compared with other treatments in Maine, Nebraska, Washington, and Mississippi (OR for receiving tube feeding $1.00,1.50,3.08$, and 5.49 respectively). In Wisconsin and Missouri (OR 1.66 and 2.82), a proxy had to be specifically granted power to refuse $\mathrm{ANH}$, but not other treatments. Furthermore, in Missouri, ANH was specifically excluded from treatments that could be refused through a living will and clear and convincing evidence of a person's treatment refusal is required for refusal of any life-sustaining treatment, as it is in New York (OR 5.63). New York's proxy law also required the healthcare agent to have "reasonable knowledge" of wishes regarding ANH. Finally, in Ohio (OR 5.83), refusal of ANH was subject to numerous restrictions that did not exist for refusal of other treatments, including determination by two physicians that ANH was not necessary for pain control, written preauthorization of ANH in capital letters, and a qualifying medical condition of permanent unconsciousness for 12 months or more. In South Dakota (OR 1.52), ANH refusal was subject to preauthorization, qualifying medical conditions, or clear and convincing evidence of the patient's wishes. 
Table 1. Characteristics of Study Population $(\mathrm{N}=57,029)$

\begin{tabular}{|c|c|c|c|c|c|c|c|c|c|c|c|}
\hline \multirow[b]{2}{*}{ State } & $\begin{array}{l}\text { Number } \\
\text { Studied }\end{array}$ & $\begin{array}{l}\text { Tube } \\
\text { Feeding }\end{array}$ & $\begin{array}{l}\text { White } \\
\text { Race }\end{array}$ & Dementia* & $\begin{array}{l}\text { Parkinson's } \\
\text { Disease }\end{array}$ & Stroke & $\begin{array}{l}\text { Living } \\
\text { Will }\end{array}$ & $\begin{array}{c}\text { Medical Power } \\
\text { of Attorney }\end{array}$ & $\begin{array}{c}\text { Feeding } \\
\text { Restriction }\end{array}$ & $\begin{array}{l}\text { DNH } \\
\text { Order }\end{array}$ & $\begin{array}{l}\text { DNR } \\
\text { Order }\end{array}$ \\
\hline & & & & & & (\%) & & & & & \\
\hline ME & 1,552 & 7.4 & 98.5 & 77.6 & 8.8 & 25.8 & 21.0 & 37.5 & 6.2 & 8.7 & 81.3 \\
\hline MO & 16,402 & 19.8 & 88.9 & 65.4 & 9.0 & 22.5 & 14.4 & 22.2 & 7.7 & 2.5 & 41.9 \\
\hline MS & 3,315 & 40.2 & 68.8 & 72.9 & 8.0 & 39.1 & 3.8 & 5.3 & 1.7 & 1.0 & 43.2 \\
\hline NE & 2,381 & 12.5 & 95.3 & 29.0 & 5.7 & 12.7 & 3.5 & 19.9 & 3.0 & 1.5 & 34.0 \\
\hline NY & 19,286 & 34.9 & 82.6 & 81.4 & 10.0 & 29.5 & 3.6 & 17.3 & 3.7 & 2.1 & 59.3 \\
\hline $\mathrm{OH}$ & 4,180 & 33.9 & 86.1 & 76.9 & 10.3 & 32.0 & 11.1 & 22.3 & 7.4 & 5.5 & 59.9 \\
\hline SD & 868 & 11.8 & 97.8 & 66.0 & 11.6 & 31.2 & 8.8 & 33.1 & 12.4 & 5.1 & 77.3 \\
\hline WA & 7,408 & 20.9 & 96.9 & 65.0 & 10.2 & 34.9 & 10.3 & 31.0 & 19.9 & 14.1 & 89.1 \\
\hline WI & 1,637 & 10.1 & 97.9 & 82.5 & 10.8 & 24.2 & 3.1 & 36.9 & 26.9 & 17.5 & 81.1 \\
\hline Totals & 57,029 & 26.2 & 87.4 & 71.3 & 9.5 & 28.0 & 8.7 & 21.6 & 8.0 & 4.6 & 57.7 \\
\hline
\end{tabular}

*Alzheimer's disease or other dementia, type not specified.

${ }^{\dagger}$ Specific directive not to provide tube feeding.

Note: $\mathrm{DNH}=$ do not hospitalize; DNR $=$ do not resuscitate.

Since 1994, there have been changes in statutory provisions regarding ANH in Maine and Mississippi. In Mississippi, a healthcare agent is specifically permitted to refuse ANH, whereas previous legislation was silent on that point; Maine has eliminated qualifying medical conditions.

\section{DISCUSSION}

This study has demonstrated significant variation among nine states in the use of tube feeding in nursing home resi-

Table 2. Likelihood of Having Tube Feeding: Clinical, Epidemiological, and Geographic Variables

\begin{tabular}{|c|c|c|}
\hline Variable & Odds Ratio & $P$-value \\
\hline Feeding restriction in advance directive & 0.41 & $<.001$ \\
\hline White race & 0.45 & $<.001$ \\
\hline Alzheimer's disease & 0.47 & $<.001$ \\
\hline Dementia (type not specified) & 0.67 & $<.001$ \\
\hline Living will & 0.68 & $<.001$ \\
\hline Medical power of attorney & 0.75 & $<.001$ \\
\hline DNH order & 0.86 & .017 \\
\hline Male sex & 0.87 & $<.001$ \\
\hline Other legal oversight & 0.91 & .079 \\
\hline Older age & 0.98 & $<.001$ \\
\hline Existence of legal guardian & 0.99 & .766 \\
\hline Parkinson's disease & 1.07 & .059 \\
\hline DNR order & 1.11 & $<.001$ \\
\hline Stroke & 2.45 & $<.001$ \\
\hline Maine & 1.00 & - \\
\hline Nebraska & 1.50 & .001 \\
\hline South Dakota & 1.52 & .0048 \\
\hline Wisconsin & 1.66 & $<.001$ \\
\hline Missouri & 2.82 & $<.001$ \\
\hline Washington & 3.08 & $<.001$ \\
\hline Mississippi & 5.49 & $<.001$ \\
\hline New York & 5.63 & $<.001$ \\
\hline Ohio & 5.83 & $<.001$ \\
\hline
\end{tabular}

Note: $\mathrm{DNH}=$ do not hospitalize; DNR $=$ do not resuscitate. dents with advanced cognitive impairment. It is not possible to know whether these results can be generalized to patterns among all 50 states, but the striking variation suggests that broader regional differences exist. Regional variation has been described for other treatments. Data published in 1987 demonstrated extremely wide regional variations in the hysterectomy rate that could not be explained by medical factors alone. These variations were believed to reflect physician uncertainty as to proper indications for this surgery. ${ }^{19}$ A striking regional variability exists for radical prostatectomy as well. ${ }^{20}$

Alzheimer's disease and other dementias were negatively associated with tube feeding, in contrast to stroke, which was positively associated; this difference is most likely due to a greater tendency to forgo tube feeding in progressive neurological disease than in stroke, when dysphagia is potentially reversible. DNR order was positively associated, whereas DNH order was negatively associated, with tube feeding. A decision not to hospitalize is likely to reflect an overall decision to limit medical intervention, whereas a DNR order might reflect a specific desire to avoid CPR while still desiring other treatments. Also, in keeping with the Patient Self Determination Act of 1991, DNR orders are likely to be discussed on admission to the nursing home, when a new resident is likely to be in better overall health. However, the association for both DNR and DNH, although statistically significant, is not particularly strong.

The analyses presented here are limited in part by the accuracy of the MDS records. While all variables achieved good interobserver reliability, ${ }^{16,21}$ it is not known how well the staff performing the assessments fully investigate the presence of advance directives. However, it is possible that these limitations apply equally to all states analyzed. Furthermore, presence of feeding tube and demographic variables, which were the main focus of analysis, were objective and unlikely the source of state-by-state error.

A limitation of the analysis is the lack of information in the database about the indication for tube feeding. Some residents might have received tube feeding because of inability to eat and drink, others because of inadequate intake due to staffing limitations, and still others for contro- 
versial indications, such as aspiration pneumonia. ${ }^{14,22-23}$ Given the nature of this problem, it is likely that such information would be difficult to obtain by other methods, such as chart review of direct interviews of medical staff, as well.

Another limitation was the inability to determine prevalence of tube feeding among residents who subsequently died. If the indication for tube feeding were life-sustaining treatment, those without it would theoretically die sooner and would therefore be underrepresented in a prevalence study. In this argument, any factor that reduced tube feeding would skew the results towards a higher prevalence among "survivors." This argument assumes that tube feeding increases survival, but this is not supported by existing data. ${ }^{24,25}$

Despite these limitations, the geographic variations are significant and we could find no evidence that the variations can be explained by medical factors. Differences in state law could play a role, although these differences are complex and difficult to quantify. The OR for tube feeding was highest in Ohio, New York, and Mississippi. More stringent standards exist in Ohio and New York, but Mississippi, by contrast, arguably has the least stringent law of all nine states. Missouri law has been the subject of much controversy with regard to decision making for $\mathrm{ANH}$, but in that state the OR for tube feeding was significantly lower than four of the other states, including Washington, which permits application of the broad "best interests" standard when the patient's wishes are not known. Although a healthcare agent in Washington must be guided by the patient's clearly expressed wishes, this requirement applies to all treatments, including ANH. Likewise, statutory definitions of "terminal illness," a qualifying medical condition in Washington, might exclude individuals with advanced dementia. This limitation also applies in Maine and Ohio, which had the lowest and highest OR, respectively.

Failure of variations in state law to account completely for variations in tube feeding prevalence could be due to inadequate physician knowledge of the law. ${ }^{8}$ Treatment decisions for nursing home residents are subject to regulatory oversight, which might in part compensate for this, but decisions to institute long-term tube feedings are often made prior to nursing home admission in settings with little or no legal scrutiny, and nonlegal factors might be quite important. One possibility is race, which was among the most strongly associated factors-white residents were less than half as likely as non-whites to have tube feeding. This difference existed even after taking into account the existence of advance directives, which are generally less common among racial and ethnic minorities. ${ }^{26-28}$ Race could have been a factor in the high prevalence of tube feeding in Mississippi, where $24 \%$ of the population 65 and older is black, compared with $9.6 \%$ for New York and Ohio, $7.3 \%$ for Missouri, and less than 2\% for the other states in this study. ${ }^{29}$ This is consistent with recent findings in hospitalized patients with advanced dementia, ${ }^{25}$ findings that racial and ethnic minorities are more likely to express a desire for life support than whites, ${ }^{28,30-31}$ and data indicating that black physicians are less likely than white physicians to view tube feeding in the terminally ill as "heroic." 32 It is likely that the proportion of black physicians paralleled general population characteristics in each state, but demographic features of physicians are lacking in our database and more study of this factor is warranted.
Socioeconomic factors could be a factor, but we were unable to determine socioeconomic status of the subjects in this analysis. Insurance data, which sometimes reflect socioeconomic status, were not analyzed because Medicaid very often pays for care of older people in nursing homes even if the patient previously was affluent or has affluent relatives. Likewise, it is difficult to discern among multiple payment sources in the MDS data.

Physician uncertainty about the medical indications for tube feeding is probably at least as great as previously suggested in the case of hysterectomy. ${ }^{17}$ In the experience of the authors, decisions about tube feeding in advanced dementia are frequently dependent upon recommendations of radiologists or speech therapists who perform swallowing evaluations, or are made by the physician for unproved or controversial indications, such as prevention of pneumonia. ${ }^{14,22-23}$ However, there is no reason to expect that lack of knowledge about the indications for tube feeding follows state lines, and we had no information on demographic variables of physicians or others involved in tube feeding decisions.

In conclusion, wide regional variations exist in the use of tube feeding among nursing home residents with severe cognitive impairments. Data from Wisconsin need to be interpreted with caution because they may not be representative of statewide practice, but one cannot assume that data from any individual state are representative of the state as a whole. Although unmeasured or unmeasurable medical factors could exist in individual circumstances, our database does not suggest that disease patterns differed among states. Rather, it is likely that differences in the law or its interpretation, or demographic factors, such as sex and race, have a greater impact. Physician uncertainty about the indications could cause a lack of uniformity in its application. More study is needed to determine if physician characteristics, such as race, attitudes, or knowledge have an impact, and to clarify medical standards for the use of tube feeding in this population. Likewise, attention should be given to the persistence of the more stringent legal standards applied to ANH as compared with other end-of-life treatments.

\section{ACKNOWLEDGEMENT}

The authors wish to acknowledge Steve Miles, MD, for his thoughts on the subject matter.

\section{REFERENCES}

1. The Hastings Center. Guidelines on the termination of life-sustaining treatment and the care of the dying. Bloomington \& Indianapolis, IN: University Press, 1987, pp 59-69.

2. American Medical Association. Decisions near the end of life. Current Opinions of the Council on Ethical and Judicial Affairs. Chicago: American Medical Association, 1986.

3. American Nurses' Association. Guidelines on withdrawing or withholding food and fluid. Biolaw Update 1988;2:1123-1126.

4. American College of Physicians. American College of Physicians Ethics Manual. Part 2: The physician and society; research; life-sustaining treatment; other issues. Ann Intern Med 1989;111:327-335.

5. Cruzan v. Director, Missouri Department of Health, 497 U.S. 261,280 (1990).

6. Asch DA, Faber-Langendoen K, Shea JA et al. The sequence of withdrawing life-sustaining treatments from patients. Am J Med 1999;107:153-156.

7. Weissman DE, Ambuel B, Norton AJ et al. A survey of competencies and concerns in end-of-life care for physicians. J Pain Symptom Manage 1998;15:82-90.

8. Solomon MZ, O'Donnell L, Jennings B. Decisions near the end of life: Professional views on life sustaining treatments. Am J Pub Health 1993;83:14-22. 
9. Cruzan v. Director, Missouri Department of Health, 497 U.S. 261,279 (1990).

10. Washington v. Glucksberg, 117 S.Ct. 2258, 2270 (1997).

11. N.Y. Pub. Health Law $\$ 2982(2)(b)$.

12. MO. Ann. Stat. $\$ 459.010(3)$.

13. Ohio Rev. Code Ann. $\$ 1337.13$ (E).

14. Ahronheim JC. Artificial nutrition and hydration in the terminally ill patient. Clin Geriatr Med 1996;12(2):379-391.

15. Morris JN, Hawes C, Fries BE et al. Designing the National Resident Assessment Instrument for nursing facilities. Gerontologist 1990;30(3):293-307.

16. Hawes C, Morris JN, Phillips CD et al. Reliability estimates for the Minimum Data Set for nursing home resident assessment and care screening (MDS). Gerontologist 1995;35(2):172-178.

17. Morris JN, Fries BE, Mehr DR et al. MDS Cognitive Performance Scale. J Gerontol 1994;49:M174-M182.

18. SAS Institute. SAS Language, Version 6. Cary, NC: SAS Institute, 1990.

19. Carlson KJ, Nichols DH, Schiff I. Indications for hysterectomy. N Engl J Med 1993;328:856-860.

20. Lu-Yao GL, McLerran D, Wasson J et al. An assessment of radical prostatectomy. JAMA 1993;269:2633-2636.

21. Sgadari A, Morris JN, Fries BE et al. Efforts to establish the reliability of the Resident Assessment Instrument. Age Ageing 1997;26(Suppl 2):27-31.

22. Finucane TE, Bynum JP. Use of tube feeding to prevent aspiration pneumonia. Lancet 1996;348:1421-1424.

23. Finucane TE. Tube feeding in patients with advanced dementia: A review of the evidence. JAMA 1999;282:1365-1370.
24. Mitchell SL, Kiely DK, Lipsitz LA. The risk factors and impact on survival of feeding tube placement in nursing home residents with severe cognitive impairment. Arch Intern Med 1997;157:327-332.

25. Meier DE, Ahronheim JC, Morris J et al. High short-term mortality in hospitalized patients with advanced dementia: Lack of benefit of tube-feeding. Arch Intern Med. In press 2001.

26. Eleazer GP, Hornung CA, Egbert CB et al. The relationship between ethnicity and advance directives in a frail older population. J Am Geriatr Soc 1996; 44:938-943.

27. Sulmasy DP, Song KY, Marx ES et al. Strategies to promote the use of advance directives in a residency outpatient practice. J Gen Intern Med 1996; 11:657-663.

28. Hopp FP, Duffy SA. Racial variations in end-of-life care. J Am Geriatr Soc 2000;48:658-663.

29. U.S. Census Bureau. Population Estimates for the U.S., Regions, and States by Selected Age Groups and Sex: Annual Time series, July 1, 1990 to July 1, 1999 [On-line]. Available: http://www.census.gov/population/estimates/state/ st-99-09.txt, 2000.

30. Garrett JM, Harris RP, Norburn JK et al. Life-sustaining treatments during terminal illness: Who wants what? J Gen Intern Med 1993;8:361-368.

31. O'Brien LA, Siegert EA, Grisso JA et al. Tube feeding preferences among nursing home residents. J Gen Intern Med 1997;12:364-371.

32. Mebane EW, Oman RF, Kroonen LT et al. The influence of physician race, age, and gender on physician attitudes toward advance care directives and preferences for end-of-life decision making. J Amer Geriatr Soc 1999;47:579-591. 